\title{
Undernutrition and associated common comorbidities among 6 -59 months old children
} Abu Rehan ${ }^{1}$, Surekha Kishore ${ }^{2}$, Mahendra Singh ${ }^{3}$, Yogesh Bahurupi ${ }^{4}$, Pradeep Aggarwal ${ }^{5}$, Bhavna Jain ${ }^{6}$

${ }^{1}$ Junior Resident, Department of Community and Family Medicine, All India Institute of Medical Sciences, Rishikesh; ${ }^{2} \mathrm{Head}$ and Professor, Department of Community and Family Medicine, All India Institute of Medical Sciences, Rishikesh; ${ }^{3}$ Assistant Professor, Department of Community and Family Medicine, All India Institute of Medical Sciences, Rishikesh; ${ }^{4}$ Assistant Professor, Department of Community and Family Medicine, All India Institute of Medical Sciences, Rishikesh; ${ }^{5}$ Associate Professor, Department of Community and Family Medicine, All India Institute of Medical Sciences, Rishikesh; ${ }^{6}$ Senior Resident, Department of Community and Family Medicine, All India Institute of Medical Sciences, Rishikesh, Uttarakahand

\begin{tabular}{|c|c|c|c|c|c|c|c|c|}
\hline Abstract & Introduction & Methodology & Results & Conclusion & References & Citation & \multicolumn{2}{|c|}{ Tables / Figures } \\
\hline \multicolumn{9}{|c|}{ Corresponding Author } \\
\hline \multicolumn{8}{|c|}{$\begin{array}{l}\text { Dr Abu Rehan, Department of Community and Family Medicine, All India Institute of Medical Sciences, } \\
\text { Rishikesh, Uttarakhand } \\
\text { E Mail ID: } \underline{\text { rehanabu975@gmail.com }}\end{array}$} & 回斯回 \\
\hline
\end{tabular}

\section{Citation}

Rehan A, Kishore S, Singh M, Bahurupi Y, Aggarwal P, Jain B. Undernutrition and associated common comorbidities among 6-59 months old children. Indian J Comm Health. 2020;32(2):461-463.

Source of Funding: Nil Conflict of Interest: None declared

\section{Article Cycle}

Received: 24/04/2020; Revision: 07/05/2020; Accepted: 02/06/2020; Published: 30/06/2020

This work is licensed under a Creative Commons Attribution 4.0 International License.

\section{Abstract}

Background: Undernutrition has long been a major public health concern in developing country like India as a leading cause of child morbidity and mortality. Aim \& Objectives: To assess undernutrition in under five children and various associated factors affecting it. Methods and Material: A community based cross sectional study was conducted among 400 under five children in Rishikesh. Results: The prevalence of underweight was $37.3 \%$, stunting was $43.3 \%$ and wasting was $24.5 \%$ respectively. Common morbidity emerged as significant predictors of under nutrition. Conclusion: The burden of common morbidities and prevalence of malnutrition among under-five children in this community is very high.

\section{Keywords}

\section{Undernutrition; Diarrhea; ARI}

\section{Introduction}

"The World Health Organization (WHO) estimates that malnutrition causes 1 million child mortality which share 54 percent of total child mortality worldwide(1) and childhood undernutrition is the cause for about $35 \%$ of all deaths of children under the age of five years worldwide.(2) Deficiencies are not only the result of inadequate dietary intake but diseases can impair absorption of nutrients and reduce appetite. Poor growth can be aggravated by increase in episode of infectious diseases like diarrhoea, upper respiratory tract infection, fever and infestation with intestinal worms. (3) In Uttarakhand, as per NFHS - 4 (2015-16) prevalence of underweight, stunting and wasting among $<5$ year of age children are $26.6 \%, 33.5 \%$ and $19.5 \%$ respectively.

\section{Aims \& Objectives}

1. To assess prevalence of undernutrition.

2. To assess common comorbidities associated with undernutrition.

\section{Material \& Methods}

A community based cross-sectional study was conducted in urban and rural areas of Rishikesh, Uttarakhand, from June 2019 to October 2019. Study participants were all 659 months old children of Rishikesh, Uttarakhand. Stunting is an important indicator of chronic undernutrition as it tells about growth restriction (4). It is more common than wasting and all the risk factors for wasting and underweight are also associated with it (5). So, sample size was calculated taking prevalence of stunting in urban and rural areas. Assuming prevalence of stunting in urban area as $32.5 \%$ and rural area as $34 \%$ (NFHS-4 data of Uttarakhand) (6), 95\% confidence interval (Cl) and $10 \%$ absolute precision sample size was calculated as 168 for urban and 173 for rural areas. Considering 10\% non-response rate the final sample size came out to be 200. As a result, 200 Children from urban areas and 200 children from rural areas of Rishikesh Uttarakhand were taken making a total sample size of 400 . A predesigned, 
pretested, semi structured questionnaire was used to collect data on socio demographic and various other factors of the study participants followed by anthropometric measurement. Study was ethically approved by ethical committee of institute. The protocol and importance of study was explained to the parents of study participants before recruitment into the study followed by signed informed consent by parents.

Sampling Technique: The study sample is obtained by multistage sampling method. Total population of Rishikesh is 260343 people, $52.9 \%$ population (137943) residing in urban area and $47.1 \%$ population (122400) residing in rural area. It has 26 wards in urban area and 87 villages in rural area. According to 2011 census total household in India is 24.84 crore and total 0-6 years children is 16.45 crore. Hence probability of under five children per households is $=16.45 \mathrm{Cr} / 24.84 \mathrm{Cr}=0.66$ (among 3 households there is chances of 2 under five children). Hence, we covered 300 households in urban and 300 household in rural areas. In urban area five wards (ward 1, 3, 4, 10, 13) were selected by simple random sampling ( $18.5 \%$ of total urban population). In rural areas five villages (Shyampur, Shiddar wala, Sahab nagar, Raiwala, Garhi maychak) were selected by simple random sampling (19.5\% of total rural population). Systematic random sampling was used to find out the households for survey for equal probability chance. Data was entered into excel sheet and analyzed using SPSS version 23 .

\section{Results}

(Table 1) depicts prevalence of underweight, stunting and wasting as $37.3 \%, 43.3 \%$ and $24.5 \%$ respectively in under five children. Underweight and stunting was more prevalent in urban areas than rural areas being $40.5 \% \mathrm{~V} / \mathrm{s}$ $35.0 \%$ and $46.5 \% \mathrm{~V} / \mathrm{s} \quad 40.0 \%$ respectively. Whereas wasting was more prevalent in urban areas $(27 \% \mathrm{~V} / \mathrm{s}$ $22.0 \%)$ as compared to rural areas and these differences were not statistically significant.

(Table 2) depicts that stunting and wasting was more in children who were not vaccinated (55.5\% \& 33.3\%) respectively. Wasting was significantly more in children who had episode of diarrhea in last year (26.1\%). Stunting and wasting was more prevalent in children who had more than three episodes of fever in last year (48.0\% \& 28.2\%) respectively. Stunting and wasting was also high in children who had more than three episodes of cough and cold in a year $(45.8 \% \& 28.5 \%)$ respectively. Stunting and wasting was more prevalent $(47.3 \% \& 26.3 \%)$ respectively in children who had history of worm infestation.

\section{Discussion}

In present study, prevalence of underweight was $37.3 \%$, stunting $43.3 \%$ and wasting $24.5 \%$ respectively. This data was found to be comparable with the data of NFHS 4(6) in India, according to which prevalence of underweight, stunting and wasting were $36 \%, 38 \%$, and $21 \%$ respectively but was high if compared with the findings of
Uttarakhand NFHS 4 data where underweight, stunting and wasting were found to be $26.35 \%, 33.5 \%$ and $19.5 \%$ respectively. Similar findings were shown by Anwar F et al(7) (2013) from Varanasi and Meshram II et al(8) (2016) from Surat, being prevalence of underweight, stunting, wasting to be $35.2 \%, 43.1 \%, 31.5 \%$ and $44 \%, 39 \%$ and $22.5 \%$ respectively.

Vaccination is very crucial for preventing infectious diseases, which can lead to undernutrition in under five children. Similarly, in present study, 93.0\% children were fully vaccinated. Stunting and wasting were more in children who were not vaccinated $(55.5 \%, 33.3 \%)$ as compared to those who were fully vaccinated $(42.7 \%$, $23.9 \%)$. Similar to this finding, Ray SK et al(9) in Kolkata found that proper implementation of UIP immunization was associated with decrease prevalence of malnutrition. In present study, history of common childhood illnesses (diarrhea, ARI, fever)(10) were very high in under five children and it is well known that recurrent infection can lead to undernutrition among children. $90.7 \%$ children suffered from diarrhea in last year. Present study also revealed that stunting and wasting were more prevalent in children who had more than three episodes of fever, cough and cold in past one year from study period. Similar to these findings, Meshram I et al(10) (2012) in tribal areas of India, revealed that fever and ARI were most common morbidity among the children followed by diarrhea and these morbidity had 1.3 times higher risk of underweight and wasting. Ramachandran $P$ et al analyzed data from NFHS-3 and reported that children who had stunting with wasting, had the highest relative risk of morbidity due to infection. Ray SK et al(9) in Kolkata observed that standard case management of diarrhea and ARI may reduce malnutrition of under-five children. In present study, $14.2 \%$ children had worm infestations in past and stunting as well as wasting were more prevalent $(47.3 \%, 26.3 \%)$ in these children with a history of worm infestations. Ray SK et al(9) in Kolkata revealed that periodic deworming may reduce risk of developing undernutrition in under five children

\section{Conclusion \& Recommendation}

Present study shows that almost half of under five children had chronic malnutrition and one fourth had acute malnutrition. Underweight, stunting and wasting were found to be more than national figures. Primary immunization was satisfactory in the study areas and majority of children were completely immunized. This study also documents that there was high burden of communicable diseases like ARI, Diarrheal diseases and worm infestation. Majority of children had symptom of fever in last year.

\section{Relevance of the study}

Despite of government scheme and efforts, still prevalence of malnutrition is very high. 


\section{Authors Contribution}

All authors have contributed equally.

\section{References}

1. Trehan I, Goldbach HS, LaGrone LN, Meuli GJ, Wang RJ, Maleta KM, Manary MJ. Antibiotics as part of the management of severe acute malnutrition. Malawi Med J. 2016 Sep;28(3):123-130. PubMed PMID: 27895846; PubMed Central PMCID: PMC5117002.[PubMed]

2. Pruss-Ustun A, World Health Organization. Safer water, better health: costs, benefits and sustainability of interventions to protect and promote health.

3. Black RE, Allen LH, Bhutta ZA, Caulfield LE, de Onis M, Ezzati M, Mathers $C$, Rivera J. Maternal and child undernutrition: global and regional exposures and health consequences. Lancet. 2008 Jan 19;371(9608):243-60. doi: 10.1016/S0140-6736(07)61690-0. Review. PubMed PMID: 18207566.[PubMed].

4. Marriott BP, White AJ, Hadden L, Davies JC, Wallingford JC. How well are infant and young child World Health Organization (WHO) feeding indicators associated with growth outcomes? An example from Cambodia. Matern Child Nutr. 2010 Oct;6(4):358-73. doi: 10.1111/j.1740-8709.2009.00217.x. PubMed PMID: 21050390 PubMed Central PMCID: PMC6860499.[PubMed].

5. Martorell R, Young MF. Patterns of stunting and wasting: potential explanatory factors. Adv Nutr. 2012 Mar 1;3(2):227-33. doi: 10.3945/an.111.001107. Review. PubMed PMID: 22516733; PubMed Central PMCID: PMC3648726. [PubMed].

6. http://rchiips.org/NFHS/factsheet NFHS-4.shtml

7. Anwar F, Gupta MK, Prabha C, Srivastava RK. Malnutrition among rural Indian children: An assessment using web of indices. Int J Public Health Epidemiol. 2013;2(4):78-84.

8. Meshram II, Rao KM, Reddy CG, Sharad KS, Sreerama KK, Hari KR. Prevalence of under nutrition and its predictors among under 5-year children in Surat region, Gujarat, India. Journal of Clinical Nutrition \& Dietetics. 2016; 2:1-2.

9. Ray SK, Maji S, Lahiri SK. A Longitudinal Study of Morbidity Pattern and Nutritional status of under Five Children in a Slum Community of Kolkata. Skin. 2014 Aug;19(6.44):388.

10. Meshram II, Arlappa N, Balakrishna N, Mallikharjuna Rao K, Laxmaiah A, Brahmam GN. Trends in the prevalence of undernutrition, nutrient and food intake and predictors of undernutrition among under five year tribal children in India. Asia Pac J Clin Nutr. 2012;21(4):568-76. PubMed PMID: 23017315. [PubMed].

\section{Tables}

\section{TABLE 1 DISTRIBUTION OF UNDER FIVE CHILDREN ACCORDING TO PREVALENCE OF UNDERNUTRITION}

\begin{tabular}{|c|c|c|c|c|}
\hline \multirow[t]{2}{*}{ Variables } & \multicolumn{2}{|c|}{ Areas } & \multirow{2}{*}{$\begin{array}{c}\text { Total }(\mathrm{N}=400) \\
\text { No }(\%)\end{array}$} & \multirow{2}{*}{$\begin{array}{l}\text { Chi square value, } \\
\text { df, } P \text { value }\end{array}$} \\
\hline & Urban $(\mathrm{N}=200)$ No $(\%)$ & Rural $(\mathrm{N}=200)$ No $(\%)$ & & \\
\hline \multicolumn{5}{|l|}{ Underweight } \\
\hline Underweight $(<-2 \mathrm{SD})$ & $81(53.6)$ & $70(46.4)$ & $151(37.7)$ & \multirow{2}{*}{$\begin{array}{c}\text { Chi square:1.28, Df: } 1, P: \\
0.25\end{array}$} \\
\hline Normal & $119(47.8)$ & $130(52.2)$ & 249 (62.3) & \\
\hline \multicolumn{5}{|l|}{ Stunting } \\
\hline Stunting $(<-2$ SD) & $93(53.8)$ & $80(46.2)$ & $173(43.3)$ & \multirow{2}{*}{$\begin{array}{c}\text { Chi square: } 1.72, \text { Df: } 1, \mathrm{P}: \\
0.189\end{array}$} \\
\hline Normal & $107(47.1)$ & 120 (52.9) & $227(56.7)$ & \\
\hline \multicolumn{5}{|l|}{ Wasting } \\
\hline Wasting $(<-2$ SD) & $54(55.1)$ & $44(44.9)$ & $98(24.5)$ & \multirow{2}{*}{$\begin{array}{c}\text { Chi square:1.35, Df: } 1, P: \\
0.24\end{array}$} \\
\hline Normal & $146(48.3)$ & $156(51.7)$ & $302(75.5)$ & \\
\hline
\end{tabular}

TABLE 2 STUNTING AND WASTING IN RELATION TO COMMON MORBIDITIES IN UNDER FIVE CHILDREN.

\section{Stunting and wasting in under five children in relation to vaccination status}

\begin{tabular}{|c|c|c|}
\hline Not vaccinated & $5(55.5 \%)$ & $4(44.5 \%)$ \\
\hline Partially vaccinated & $9(47.3 \%)$ & $10(52.7 \%)$ \\
\hline Fully vaccinated & $159(42.7 \%)$ & $213(57.3 \%)$ \\
\hline Total & $173(43.3 \%)$ & $227(56.7 \%)$ \\
\hline
\end{tabular}

Chi-square-.726, df-2, Sig.--696

Stunting and wasting in under five children in relation to episode of diarrhea in last yea

\begin{tabular}{|l|c|c|}
\hline Yes & $159(43.8)$ & $204(56.1)$ \\
\hline No & $14(37.8)$ & $23(62.2)$ \\
\hline Total & $173(43.3)$ & $227(56.7)$ \\
\hline
\end{tabular}

Chi-square-0.487, Df-1, Sig-0.485

Stunting and wasting in under five children in relation to episode of fever in last year

\begin{tabular}{|c|c|c|c|c|c|}
\hline \multicolumn{6}{|c|}{ gin unaer ine crilaren in r } \\
\hline None & $3(30.0)$ & $7(70.0)$ & $1(10.0)$ & $9(90.0)$ & $10(2.5)$ \\
\hline 1 episode & 18(40.9) & 26(59.1) & $10(22.7)$ & $34(77.3)$ & $44(11.0)$ \\
\hline 2-3 episodes & $89(41.3)$ & $126(58.7)$ & $50(23.2)$ & $165(54.6)$ & 215(53.8) \\
\hline$>3$ episodes & $63(48.0)$ & $68(52.0)$ & $37(28.2)$ & $94(71.8)$ & $131(32.8)$ \\
\hline Total & $173(43.3)$ & $227(56.7)$ & $98(24.5)$ & $302(75.5)$ & $400(100.0)$ \\
\hline \multicolumn{3}{|c|}{ Chi-square-2.366, df-3, Sig-0.500 } & \multicolumn{3}{|c|}{ Chi-square-2.384, Df-3, Sig.-.497 } \\
\hline \multicolumn{6}{|c|}{ Stunting and wasting in under five children in relation to episode of cough/cold in last year } \\
\hline None & $2(20.0)$ & $8(80.0)$ & $1(10.0)$ & $9(90.0)$ & $10(2.5)$ \\
\hline 1 episode & 16(40.0) & $24(60.0)$ & $8(20.0)$ & $32(80.0)$ & $40(10.0)$ \\
\hline 2-3 episodes & $94(43.3)$ & $123(56.7)$ & $51(23.5)$ & $166(76.5)$ & $217(54.3)$ \\
\hline >3 episodes & $61(45.8)$ & $72(54.2)$ & $38(28.5)$ & $95(71.5)$ & 133(33.2) \\
\hline Total & $173(43.3)$ & $227(56.7)$ & $98(24.5)$ & $302(75.5)$ & $400(100.0)$ \\
\hline \multicolumn{3}{|c|}{ Chi-square-2.745, Df-3, Sig.-0.432 } & \multicolumn{3}{|c|}{ Chi-square-2.883, Df-3, Sig.-.410 } \\
\hline \multicolumn{6}{|c|}{ Stunting and wasting in under five children in relation to worm infestation } \\
\hline Yes & $27(47.3)$ & $30(52.7)$ & $15(26.3)$ & $42(73.7)$ & $57(14.2)$ \\
\hline No & $146(42.5)$ & $197(57.5)$ & $83(24.1)$ & $260(75.9)$ & $343(85.8)$ \\
\hline Total & $173(43.3)$ & $227(56.7)$ & $98(24.5)$ & $302(75.5)$ & $400(100.0)$ \\
\hline \multicolumn{3}{|c|}{ Chi-square-.459, df-1, Sig.-.498 } & \multicolumn{3}{|c|}{ Chi-square-0.118, Df-1, Sig.-0.730 } \\
\hline
\end{tabular}

Chi-square-2.366, df-3, Sig-0.500 $173(43.3)$ $227(56.7)$

\begin{tabular}{|c|}
\hline $3(33.3 \%)$ \\
\hline $6(31.5 \%)$ \\
\hline $89(23.9 \%)$ \\
\hline $98(24.5 \%)$ \\
\hline Chi-square-0.961
\end{tabular}

\begin{tabular}{|c|c|}
\hline $6(66.7 \%)$ \\
\hline $13(68.5 \%)$ \\
\hline $283(76.1 \%)$ \\
\hline $302(75.5 \%)$ \\
\hline
\end{tabular}

$9(2.3)$
$19(4.8)$
$72(93.0)$
$00(100.0)$

Chi-square-0.961, Df-2, Sig.-0.618

\begin{tabular}{|c|c|c|}
\hline $95(26.1)$ & $268(73.9)$ & $363(90.7)$ \\
\hline $3(08.1)$ & $34(91.9)$ & $37(9.3)$ \\
\hline $98(24.5)$ & $302(75.5)$ & $400(100.0)$ \\
\hline
\end{tabular}
Chi-square-5.922, df-1, Sig.-0.015 